\title{
Konteyner Limanlarında RFID Teknolojisinin Kullanımına Yönelik Bir Fayda Maliyet Analizi Çalışmasi ${ }^{1}$
}

\author{
DOI: $10.26466 /$ opus. 833607 \\ *
}

\section{Serdar Alnıpak ${ }^{*}$}

* Dr. Öğr. Üyesi, Nişantaşı Üni., İİ.B.F, Havacılık Yönetimi (İng.) Böl., İstanbul/Türkiye E-Posta: serdara76@yahoo.com

ORCID: $\quad$ 0000-0002-5722-9960

\section{Öz}

Bilgi teknolojilerinde sürekli bir değiş̧im ve gelişme süreci yaşanmaktadır. Bu sürecin her sektörde olduğu gibi konteyner taşımacılı̆̆ı ve limanları üzerinde de etkileri bulunmaktadır. Rekabet avantajını korumayı ve müşterilerine kaliteli hizmet vermeyi amaçlayan konteyner limanları, operasyon verimliliklerini, yük ve liman güvenliklerini arttırmaya yönelik olarak bilgi teknolojilerinden yararlanmaktadır. Bu teknolojilerden en önemlilerinden birisi Radyo Frekansı Tanımlama (RFID) teknolojisidir. RFID sistemleri, radyo frekanslarm kullanarak durağan ya da hareket halinde olan canlılar ve nesneleri tekil veya çoğul halde tanımlamakta kullanılmaktadır. RFID; taşıyıcı araç, ekipman, yük ve insan bazlı olarak hem otomatik hem doğru veri toplayabilen bir teknoloji olması sebebiyle liman aktivitelerinin tamaminda fayda sağlayabilmektedir. Bu teknoloji, konteyner limanlarında tanımlama, izleme ve güvenlik açısından birçok fayda sağlamaktadır. Tüm avantajları dışında dezavantajları da olan bu teknolojinin en büyük handikaplarından birisi maliyetleridir. Bu bağlamda konteyner terminalinin tüm alanlarında uygulanan, ideal yapıdaki RFID tabanlı bir sistemin ölçülebilir parametreler ile fayda-maliyet analizinin yapılarak, ilgili yatırımın ekonomikliğinin belirlenmesi önem arz etmektedir. Ayrica RFID teknolojisinin konteyner terminallerinde kullanımına yönelik akademik çalışmalar azdır. Bu çalışmada, RFID teknolojisinin konteyner limanlarında kullanımı araştıılmış ve fayda-maliyet analizi yapılmıştır. Fayda-maliyet analizi için ölçülebilir parametreler çerçevesinde; RFID teknolojisini tüm süreçlerinde kullandığı varsayılan orta ölçekli bir konteyner terminali düşünülmüştür. Illgili yatırım; 3. yılda başa baş noktasına ulaşabilmektedir. Net Bugünkü Değere göre on yılın sonunda oluşan fayda-maliyet oranı 1,63 olarak bulunmuştur.

Anahtar Kelimeler: $\quad$ RFID Teknolojisi, Konteyner Limanı, Fayda/Maliyet Analizi.

\footnotetext{
${ }^{1}$ Bu çalışma, Dr. Öğr.Üyesi Serdar Alnıpak'ın doktora tez çalışmasının bir bölümünün, yeni kaynaklar ve veriler ile revize edilmesi ile hazırlanmıştır.
} 


\title{
A Benefit-Cost Analysis Study of Usage of RFID Technology in Container Ports
}

\begin{abstract}
There is an ongoing process of change and development in information technologies. This process has also impacts on container transportation and ports as in every sector. Container ports which aim to provide high quality service to their customers and to maintain competitive advantage, utilize information technologies for increasing efficiency and security of cargo and port. One of the most important of these technologies is Radio Frequency Identification (RFID) technology. RFID systems use the radio frequencies and define the lively beings and/or objects, stable or moving, as singular or plural. RFID is a technology that gathers accurate and automated information in terms of vehicle, equipment and people; therefore it is of great use in port activities. This technology provides many benefits in container ports in terms of identification, monitoring and security. Out of all advantages, RFID technology has also disadvantages and costs are the biggest handicap. In this context it is important to apply benefit-cost analysis with measurable parameters for a container terminal where has been applied RFID technology to its all areas and determine the economy of related investment. In addition academic research on the use of RFID technology in container ports is poor. In this study, the use of RFID technology in container ports was investigated and cost-benefit analysis was performed. Within the framework of measurable parameters for cost-benefit analysis; a medium-sized container terminal that is assumed to use RFID technology in all its processes, is considered. Related investment can reach the breakeven point in the $3 r d$ year. The benefit-cost ratio occurred at the end of the ten years according to the Net Present Value was found to be 1.63.
\end{abstract}

Keywords: RFID Technology, Container Port, Benefit/Cost Analysis. 


\section{Giriş}

Uluslararası yük taşımacılığı farklı tipte taşıma türlerini içeren ve genel kapsamlı takip, dağıtım, idare ve optimizasyon gerektiren bir süreçtir (Xu, Zhen, Li ve Yue, 2017, s.1824). Giderek daha karmaşıklaşan küresel tedarik zincirlerinin yönetiminde tedarik zinciri operatörleri için izlenebilirliğin sağlanması bir öncelik haline gelmiştir. İzlenebilirlik, bir bileşenin, ürünün veya belgenin kökenini ve yerini izleme, böylece uçtan uca tedarik zincirinin görünürlügünü ve yük üzerindeki kontrolünü güçlendirmeyi ifade eder. Tüketicilerin ürün kalitesi, güvenliği ve sürdürülebilirliğine olan ilgisi artarken, nakliyeciler ürün izlemeyi geliştiren ve kesintisiz zincirler sağlayan teknolojilere yatırım yapmaktadır. Ayrıca, tedarik zinciri boyunca daha iyi izlenebilirlik, diğer faktörlerin yanı sıra stok yönetimi, varlık kullanımı, çeviklik ve risk yönetimini geliştirmektedir (Inter-Amerıcan Development Bank [IDB], 2018, s.24). Bu bağlamda güvenli bir tedarik zincirinin dokümantasyonu ve kontrolü için veri kaynakları olarak lojistik nesnelerin otomatik olarak tanımlanması ve konumlandırılmasına ilişkin talepler artmaktadır. Lojistik tüm kaynakların orijin noktasından, varış noktasına kadar çift yönlü akışını yönetmeye odaklanan çok süreçli bir endüstridir. Öte yandan, farklı nakliye araçları ve ilgili taraflar nedeniyle lojistik süreçleri genellikle karmaşıktır. Tedarik zincirlerinin izlenmesi ve yönetimi, günümüzde liman terminalleri de dahil olmak üzere küresel şirketler için önemli bir konu olarak kabul edilmektedir. İzleme ve takip sistemlerinin kullanımı, maliyetleri azaltmak ve darboğazların ve operasyonel kusurların sorunsuz bir şekilde tanımlanması için gereklidir. Lojistik ve üretim süreçlerinde farklı nesne seviyelerinin tanımlanması, konumlandırılması ve koşullarının izlenmesi için teknik sistemlerin çoklu kullanım konsepti uygulanmaktadır. Bu bağlamda bireyler, yük, mobil kaynaklar ve altyapılar takip edilebilmektedir (Kirch, Poenicke ve Richter, 2017, s.526-527). Otomatik tanımlama teknolojileri ile akıllı tanımlama, şu anda ulusal ekonominin tüm alanlarında önemli bir rol oynamaktadır (Tengler, Kolarovzski ve Kolarovszká, 2017, s.491). Etkin sistem tasarımı, kablosuz ağ iletişimlerini kullanarak merkezi kontrol, konum izleme ve gerçek zamanlı kontrol sağlanabilmektedir (Shın, Roh ve Hur, 2018, s.163). 
Farklı lojistik operasyonlarının kontrolü ve yönetimi, yüklerin izlenmesi için RFID (Radio Frequency Identification - Radyo Frekansı ile Tanımlama), GPS (Global Konumlandırma Sistemi), NFC (Yakın Alan İletişimi), RTLS (Gerçek Zamanlı Konum Belirleme Sistemi) vb. teknolojiler sıklıkla kullanılmaktadır (M'hand, Boulmakoul, Badir ve Lbath, 2019, s.221). RFID teknolojileri, radyo frekanslarını kullanarak hareketli veya hareketsiz, canlı veya cansız nesnelerin tanımlanmasında kullanılmaktadır (Özmen ve Birgün, 2011, s.81-88). Bu teknoloji pek çok sektörde olduğu gibi limancılık sektöründe de kullanılmaktadır. Taşıyıcı araç, ekipman, yük ve insan bazlı olarak hem otomatik hem doğru veri toplayabilen bir teknoloji olması sebebiyle liman aktivitelerinin tamaminda fayda sağlayabilmektedir. Konteyner limanları/terminalleri için temel olarak kimliklendirme (tanımlama), takip ve güvenlik açılarından pek çok fayda sağlayan bu teknoloji bazı açılardan dezavantajları da beraberinde getirmektedir. $\mathrm{Bu}$ dezavantajlardan en büyüğü maliyetlerdir. Pek çok avantajı beraberinde getiren RFID teknolojisine yatırım yapma kararı bu açılardan son derece stratejiktir ve ilgili yatırımın ekonomikliğinin belirlenmesi önem arz etmektedir. Bu amaçla çalışmada, konteyner terminalinin tüm alanlarında uygulanan, ideal yapıdaki RFID tabanlı bir sistemin ölçülebilir parametreler ile fayda-maliyet analizi yapılmıştır. Çalışmanın ikinci bölümünde genel hatları ile RFID teknolojisi, üçüncü bölümde ise ilgili teknolojinin konteyner terminallerinde kullanım alanları açıklanmıştır. Dördüncü bölümde belli kabuller çerçevesinde orta ölçekli bir konteyner terminali için RFID teknolojisine yönelik bir yatırımın ekonomikliği, fayda-maliyet oranı ve başabaş noktası hesaplanmıştır. Son bölümde, elde edilen değerler irdelenmiş ve önerilerde bulunulmuştur.

\section{RFID Teknolojisi}

RFID teknolojisi, radio frekanslarını kullanarak nesnelerin tekil ve otomatik olarak tanımlanmasını sağlayan bir teknolojidir. RFID inovasyonunun yıllar önce bulunmasına rağmen, masraflar tüm kullanımdaki temel sınırlama olduğu için en son on yılda ilerlemiş ve gelişmiştir (Yadav ve Jha, 2019, s.1242). Bu teknoloji elektromanyetik dalgalar yoluyla aynı anda birden fazla nesneyi ve / veya insanı 
tanımlamak, izlemek ve tespit etmek için yaygın olarak kullanılan bir otomatik tanımlama teknolojisidir. Sistemin çalışma prensibi temel olarak; etiket RF alanına girer (okuyucunun yaydığı dalgalar etikette bulunan antenle buluşarak devreleri çalıştırır), etiket tanımlayıcı bilgileri (kayıtlı kimlik kodunu ve diğer bilgileri) aktarır, okuyucu veriyi yakalar, okuyucu veriyi dijital veri haline dönüştürerek, Server'a gönderir, Server ne yapılacağına karar verir, Server okuyucuya gerekli talimatları gönderir, okuyucu veriyi etikete aktarır (Moreau, 2003, s.1-20). Bir RFID sistemi genellikle üç bileşenden oluşmaktadır; (1) tanımlanacak nesneye yerleştirilen bir etiket; (2) bununla doğrudan bağlantılı olmak zorunda kalmadan etiketle iletişim kuran bir okuyucu ve antenleri ve (3) sistemi yönetmek ve kuruluşun bilgi sistemleri ile etkileşim kurmaktan sorumlu bir ara katman yazılımı ile donatılmış bir ana sunucudur. RFID etiketleri pasif veya aktif olabilmektedir. Pasif RFID etiketlerinde dahili güç kaynağ 1 yoktur, sabit okuyuculara güvenir ve esas olarak tanımlama ve erişim kontrolü için kullanılırken, aktif RFID etiketleri pille çalışır, kendi sinyallerini yayınlar ve daha uzun okuma mesafesi sağlar, bu da onları gerçek zamanlı izleme için daha uygun hale getirmektedir. RFID sistemi ayrıca, ara katman yazılımından gelen bilgilere dayalı akıllı hizmetler sağlamak için bir bilgi sistemi ile entegre edilebilmektedir (Haddara ve Staaby, 2018, s.81). Temel olarak RFID sistemlerinin çalıştığ1 üç tip frekans vardır: düşük frekans (LF), yüksek frekans (HF) ve ultra yüksek frekans (UHF). Frekanslar LF için 125-134 kHz, HF için $13.56 \mathrm{MHz}$ ve UHF için 866-966 MHz aralığındadır (Costa, Carvalho, Fernandes, Alves ve Silva, 2017, s.1263; Tengler, vd., 2017, s.492). RFID teknolojisinin görüş alanı gerektirmemesi ve objeleri ayn anda ve bir arada hatasız okuyabilmesi gibi avantajları lojistik süreçlerde ilgili teknolojiyi barkod teknolojisine göre çok daha öne taşımaktadır (Batarlienè ve Jarašūniene, 2016, s.484). RFID teknolojisi IoT (Nesnelerin İnterneti) için en önemli olanaklardan birisidir (M'hand, vd., 2019:220). Son y1llarda lojistik operasyonları radyo sinyallerine dayalı çeşitli teknolojilerin benimsenmesine tanıklık etmiştir, örneğin bir liman alanının sınırları içindeki farklı yük tiplerini izleme ve takip için radyo frekansı ile tanımlamaya yönelik olarak (RFID) etiketleri yaygın olarak kullanılmaktadır. RFID etiketi doğrudan yüke eklenebildiği gibi liman tesislerinde hizmet veren bir nakliye aracının sürücüsü / operatörü 
tarafından da taşınabilmekte ve ilgili kişilere tanımlanabilmektedir. Nakliye araçlarının irtibatı için yaygın olarak kullanılan teknolojiler arasında hücresel ağlar ve uydu sistemleri ve daha az ölçekte de olsa WiFi, UMTS, 4G / LTE ve WiMax da bulunmaktadır. Bununla birlikte, güvenilirlik, bağlantı, sınırlı menzil, ölçeklenebilirlik ve güvenlik ile ilgili konularda hala bazı problemler bulunmaktadır (Mondragon, Mondragon ve Coronado, 2017, s.70). Ayrıca kara taşımacılı̆̆ında da yüklerin ve trafik akışının gerçek zamanlı takibine yönelik RFID, GPS ve GPRS kablosuz veri transferinin ortaklaşa kullanılmaktadır (Xu, vd.,2017, s.1825). Mevcut lojistik endüstrisinde, nakliyeciler yük konteynerinin üzerine yerleştirilmiş aktif veya pasif bir RFID etiketi kullanarak yükün mevcut konumunu izlemek için RFID sistemini kullanmaktadır. Bu teknolojinin bir dezavantajı, transponder tarafından iletilen radyo dalgalarının çeliğe nüfuz edememesidir (Bandara, Garaniya, Chin ve Leong, 2015, s.166). RFID etiketleri (RFID, tedarik zincirindeki otomasyon süreçlerini mümkün kılmaktadır ve yüklerin doğrulanmasına yardımcı olmaktadır. Konteyner tanımlaması için ISO standartları (ISO 10891 ve ISO 17363) geliştirilmiştir), e-mühürler (konteyner kapı bütünlüğü ve gümrük süreçlerine yönelik olarak), Konum teknolojilerini kullanan izleme cihazları (özellikle uydu konumlandırma (GNSS) ile uydu ve / veya hücresel iletişim teknolojileri), Konteyner Güvenlik Cihazları (CSD) (izleme cihazlarını sensörleri ile entegre kullanılmaktadır (Scholliers, Permala, Toivonen ve Salmela, 2016, s.1374). RFID teknolojisi kullanımı verimliliği, etkinliği ve rahatlığı arttırmaktadır. RFID teknolojisi aynı zamanda üretim hatlarından üretim verilerinin toplanabileceği ve daha fazla analiz için bilgi merkezine gönderilebileceğinden imalat sanayiinde de kullanılmaktadır. Büyük veri analizi, atölyelerin yönetimine yardımcı olabilecek iyi bir firsat sunmaktadır (Zhong, 2019, s.24). RFID, paletlerin, kasaların ve münferit ürünlerin yanı sıra, tedarik zinciri boyunca kutular ve konteyner gibi yeniden kullanılabilir varlıkların izlenmesini otomatikleştirmek için de kullanılmaktadır. Bu tür bir uygulama, tedarik zincirinin rekabet gücünü önemli ölçüde geliştirmektedir. RFID teknolojisi tedarik zincirlerinin teslim sürelerini düşürmektedir. RFID teknolojisinin adaptasyonundan sonra, perakendecilerin optimal sipariş miktarları azalmakta ve maliyetler düşmektedir (Yan, Liu, Liu ve Yang, 
2018, s.1-2). Bazı perakende mağazalarında, RFID etiketleri modaya uygun giysilere eklenmekte ve daha sonra her kademede müşteri eğilimlerin ve stokların takibi için kullanılmaktadır. Bununla birlikte, bu teknoloji, bir mağaza ağındaki siparişlerin izlenebilirliği ve verimliliğini arttırmakta yardımcı olmaktadır. Kısa ürün ömrü, uzun üretim süresi ve öngörü hataları tekstil endüstrisinde bulunan temel sorunlardır. $\mathrm{Bu}$ sorunları kontrol etmek için RFID teknolojisi önerilmektedir (Ali ve Haseeb, 2019, s.217). Ayrıca Endüstri 4.0 konseptinin getirdiği yeni paradigmalar çerçevesinde ürünlere yönelik veri toplama için popüler çözümlerden birisi lojistik sektöründe olduğu gibi RFID sistemidir. Endüstri 4.0, Akıllı Ürünlere dayalı üretimi temsil eden RFID tabanlı Akıllı Fabrika konseptini öne çıkarmaktadır (Mladineo, vd., 2019, s.385). Örneğin Kivi ticaretinde dünya lideri olan Zespri firması, ürün izlenebilirliğini arttırmak ve kalitesini korumak için ürünleri Yeni Zelanda'dan Belçika'ya taşıyan paletlerde konteyner sıcaklığını kaydetmek için RFID veri kaydedici etiketlerini kullanmaktadır. Bu, tedarik zincirindeki diğer aktörleri, özellikle taşıma, depolama ve dağıtımı ile ilgili olanları, süreçlerinde ve tesislerinde kullanılan teknolojiyi geliştirmeye itmiştir. Böylece Zespri Yeni Zelanda'daki bir mağazadan, bir gemideki konteynere ve Avrupa'daki bir mağazaya kadar küresel tedarik zinciri boyunca tam izlenebilirlik sağlamaktadır. Ayrıca firma bu teknolojinin kullanımı ile süreçteki hedeften sapmaları tanımlayabilmekte, kayıpları azaltmaktadır. (IDB,2018, s.25-48). Envanteri yanlış yerleştirme, birçok endüstride yaygındır ve maliyetleri arttırmaktadır. DeHoratius ve Raman (2008) çalışmasında; yıllık satışları yaklaşı 10 milyar dolar olan büyük bir kamu perakendecisinin 37 mağazasından yaklaşık 370.000 stok kaydını incenlemiş ve kayıtların \% 65'inin yanlış olduğu tespit edilmiştir. IBM tarafından hazırlanan bir raporda perakendecilerin stok yanlışlığı nedeniyle \% 1,75 oranında zarar gördüğünü göstermektedir. Radyo frekansı ile tanımlama (RFID) teknolojisi, envanter yanlış yerleştirilmesine etkili ve gelecek vaat eden bir çözüm önerisidir. RFID teknolojisinin yardımıyla, tek tek öğeler bir RFID etiketi ile izlenebilmekte ve envanter kesin bilgi ile hatasız olarak yönetilebilmektedir (Tao, Kinkeung, Wang ve Fan,2018, s.1-2). 
Konteyner Limanlarında RFID Teknolojisinin Kullanımı: Dünya ticaret artışına paralel olarak artan konteyner taşımacılığı ve buna bağlı olarak yaşanan güvenlik gereksinimleri, kapasite problemleri ve süreç otomasyonu ihtiyacı ile birden çok taşıma türü kullanımındaki yükseliş, tüm aktörler açısından daha verimli planlama ve kontrol gerekliliklerini ortaya çıkarmıştır. Konteyner trafiği hızla artmasına rağmen, konteynerleri idare eden altyapı (ekipman, prosedürler vb.) aynı ilerleme hızı ile modernize edilememektedir. Bu durum yönetimsel problemlere yol açmaktadır. Bunlar; gemiyi karaya bağlama esnasında çok fazla bekleme süresi oluşması, yetersiz kalan terminal üretkenliği, terminal kapılarında trafik sıkışıklığı, kontrol prosedürlerinde aşırı zaman kaybı, paydaşlar arasında olması gerekenden az bilgi paylaşımı, koordinasyon problemleri vb. (Tsilingiris, Psaraftis ve Lyridis, 2007, s.4-5). Sorunsuz bir yük, bilgi ve finansal kaynak akışı için denizcilik tedarik zincirleri genellikle bilgi teknolojilerine dayanmaktadır (IDB,2018, s.11). Panayides (2007) denizcilik sektörü aktörleri üzerinde yaptıkları akademik ankete göre; elektronik veri değişim (EDI) gelişmeleri, izleme ve takip sistemleri ve tedarik zinciri entegrasyon sistemleri denizcilik sektörünün öncelikli olarak ilgilendikleri ve bekledikleri küresel eğilimlerdir. Limancılık sektörü 1980'lerin ortalarından bu yana BİT (Bilgi İşlem Teknolojileri) temelli öğeleri (intranet, extranet, RFID, iletişim platformları) aşamalı olarak kullanmaktadır. RFID, hücresel ağlar, GPS / uydu sistemleri, UMTS, 4G / LTE, WiMax, araç kablosuz ağları (VANETS) ve kurumsal kaynak planlaması (ERP) gibi internet tabanlı firmalar arası sistemlerin kullanımı yaygınlaşmış ve taşımacılık ve lojistik hizmetlere destek, tedarik zinciri teknolojilerinin geniş ürün yelpazesinin zorluklarını kolaylaştırmak vb. için hem rakip hem de paydaş firmalar tarafından bu teknolojiler değerlendirilmiştir (Mondragon, vd., 2017, s.70). Konteyner terminallerinde RFID kullanımı temel olarak 3 obje üzerinden yapilır. Bunlar; konteynerler, yükleme-boşaltma ve taşıma işlemlerinde kullanılan ekipman ve araçlar (liman içi ve dışı) ve süreçte görevli insanlar'dır. Pasif ve/veya aktif etiketler bu objelere konularak temelde amaçlanan hedefler; kimliklendirme (tespit) ve takip, yük ve liman bazında güvenlik olarak özetlenebilir. Konteyner taşımacıllğında hem aktif hem pasif etiketler birlikte kullanılmaktadır. Genelde aktif etiketler 433, pasif etiketler $900 \mathrm{MHz}$ frekanslıdırlar. Konteyner üzerine konan 
aktif etiketler ISO 17363'e göre üretilmekte ve üzerine defalarca veri yazımı yapılabilmektedir. Bu etiketler pilli olduğu için belli zaman dilimlerinde uyku (sleep) modunda kalmaktadır. Konteyner için kullanılan pasif etiketler ISO 10374.2 standartlarında üretilmektedir ve 860-960 MHz frekanslıdır. Etiketleri kontrol noktalarında (liman girişçıkış kapıları, istif sahaları, rıhtım alanları, depolama bölgeleri vb.) okuyan RFID okuyucuları için sıklıkla UHF ve MF okuyucular tercih edilmektedir. Etiketlerin veri kapasitelerine ve hangi objeye konacağına bağlı olmakla beraber etiketler üzerlerinde konteyner numarası, konteynerin konum bilgileri, konteynerin ağırlı̆̆ı, yük türü, tehlikeli madde bilgileri, mühür kontrol bilgisi, hasar tespit bilgisi, boş konteyner tespit sonuçları, taşıyıcı araç bilgileri, taşıyıcı araç şoför bilgileri, taşıyıcı araç konum bilgileri konteyner elleçleme ekipmanı (vinç, iç kamyon, vagon, forklift vb.) bilgileri taşıyabilmektedirler (Abajo, 2009, s.5-11). Liman içi ve dişında kurulmuş olan okuyucuların yardımıyla konteynere, araçlara vb. eklenmiş aktif/pasif etiketlerin içindeki veriler hatasız ve otomatik olarak okunabilmekte ve okunanlar bir kablosuz ağ aracılığıyla otomatik olarak sisteme bildirebilmektedir. Kaliszewski (2018) çalışmasında 5. nesil limanları tanımlayan kriterlerden birisini RFID sistemlerini kullanma olarak belirtmiştir. RFID teknolojisi pek çok uygulamaya yönelik olarak kullanılabilmektedir. Bu uygulamalardan bazıları; aracın ücretli gişelerde durmasına gerek kalmadan otoyol geçiş ücretlerinin toplanması; fabrikaların, limanların veya lojistik merkezlerinin kapılarının yakınında bulunan kamyonların/tırların tanımlanması ve yükün yerini gösteren çeşitli bilgi işaretlerinin kullanılması; limanlarda, tren istasyonlarında ve tır terminallerinde konteynırların ve tır römorklarının tanımlanması, böylece "kayıp" konteynır ve römorklardan kaçınılması ve elleçleme ekipmanları ile yüklerin etkili bir şekilde eşleştirilmesi; araçların düzenli durma noktalarında tanımlanması (sınır geçişleri, tartım istasyonları, kontrol noktaları); iş / dinlenme programın ihlal eden sürücülerin belirlenmesi vb. (Batarlienė ve Jarašūniene, 2016, s.484). Günümüzün popüler kavramlarından birisi olan 'Akıllı Liman Konsepti'nde sensör, RFID, WSN (Kablosuz Sensör Ağı), M2M (Makineden Makineye), QR Kod teknolojileri, manyetik kimlik kartları vb. kullanımı takip, izleme ve güvenliğe yönelik sıklıkla kullanılmaktadır (M'hand, vd., 2019, s.220). 
Pek çok liman ve kuruluşta RFID tabanlı projeler uygulanmaktadır. Dünyanın en büyük, aktif RFID kullanımı Rotterdam limanındadır. Broekman Grubu limanlarına RFID tabanlı, gerçek zamanlı bir lokasyon sistemi kurmuştur. $\mathrm{Bu}$ sistem altında, her araca tekil tanımlama numarası içeren aktif RFID etiketleri takılmıştır. Sistem, terminale gelen her aracın herhangi bir zamanda nerede konumlandığı bilgisini sağlamaktadır. Şu an için yılda yüzbinlerce araç terminale giriş yapmaktadır ve sistem bu araçların takip edilmesinde ve yönetilmesinde yardımcı olmaktadır. Bu araçlar için veri toplama sürecinin otomatize edilmesi ile birlikte liman kullanımının ve üretilen işin artması, müşteri servislerinde iyileşme, müşteri memnuniyetinde artma ve aynı zamanda maliyetlerde azalma sağlanmıştır (Banks, Hanny, Pachano ve Thompson, 2007). Bremen'deki Taşımacılık Ekonomisi ve Lojistik Enstitüsü (ISL) tarafından gerçekleştirilen SICIS (Shared Intermodal Container Information System) projesi ile lojistik düğüm noktalarında, taşınan yüklerin konumunu takip etmek amaciyla RFID elektrikli etiket uygulaması yapılmaktadır. Benzer şekilde Şangay limanında, taşınan yükler RFID etiketleri vasıtasıyla teslimat noktalarında, saha girişinde ve elleçleme noktalarında izlenmektedir. Bu teknoloji ilk olarak ShanghaiSavannah Sino-American konteyner taşıma hattına uygulanmıştır $(\mathrm{Xu}$, vd., 2017, s.1825). Busan Limanı'nda gerek liman sahasinda gerek ise kapılardan kamyon geçişlerinin otomatik olarak tanınmasında radyo frekansları kullanılmaktadır. Her terminal girişinde, liman dışı araçları ve saha traktörlerini tespit eden ve izleyen kurulu bir RFID okuyucu bulunur. Terminaldeki her araç ulusal yol ağında kullanım için onaylanmış zorunlu bir RFID kartı kullanmaktadır (Mondragon, vd., 2017, s.79). Yine Busan Limanında "Yeni Liman Bazlı Konteyner Terminali"nde, elektronik geçiş ücreti tahsilatı için halihazırda kullanılmakta olan RFID teknolojisine dayanan cihazlar kullanılmaktadır. Bu sistem GPS teknolojisi ile entegre edilmektedir (Mondragon, vd., 2017, s.85). Konteyner taşıma zincirinin takibi hem tedarik zinciri yönetimi hem de güvenlik nedenleriyle gereklidir. Yetkililer, düzenlemelere uyumu sağlamak ve yasadışı malların ithalatından kaçınmak için daha fazla yük görünürlüğü/ izlenebilirliği talep etmektedir. Limanlardaki operasyonların aksaması çok maliyetli hale gelebilmektedir. Liman güvenliği, hem can ve mal üzerindeki 
doğrudan tehditlerlerden hem de tedarik zincirlerinde oluşabilecek ekonomik zararlardan dolayı büyük önem taşımaktadır. Eylül 2001'de ABD'deki terörist saldırılardan bu yana, konteynerli liman operasyonlarının güvenliğine özel önem verilerek çeşitli düzenlemeler yapılmıştır. Özellikle konteyner limanı operasyonlarını hedefleyen küresel güvenlik önlemleri arasında Uluslararası Gemi ve Liman Tesisi Güvenliği (ISPS) kodu, Konteyner Güvenlik Girişimi (CSI) ve 24 saatlik Advance Vessel Manifest Kuralı bulunmaktadır. Yüklerin izlenebilirliği ve takibi, akıllı taşımacılık lojistiği ile güvenli ve emniyetli yük taşımacılığını desteklemek için kilit unsurlardır. Konteynerlere bu teknolojilerin eklenmesi, gönderici gibi tedarik zincirine diğer tarafların dahil edilmesini gerektirir ve bu nedenle teknolojiyi uygulama kararı sadece liman paydaşları tarafından alınamaz. Bu teknolojilerin optimum kullanımı, farklı paydaşlar arasında bilgi paylaşımını gerektirmektedir (Scholliers, vd., 2016, s.1374-1375). Her yıl dünya limanlarında milyonlarca dolu ve boş konteyner dolaşımda olmakla birlikte çok azına güvenlik kontrolleri uygulanabilmektedir. Bu bağlamda terör tehdidi, hırsızlık ve kaçakçılık faaliyetleri güvenlik ihtiyacını artırmaktadır. Mevcut durumda kullanılan klasik konteyner mühürlerinin manuel kontrollerinde illegal girişimler tespit edilse de girişimin zamanını, yerini ve faillerini tespit etmek çok zordur. Spesifik ID'si ile ve taklit edilemeyen yapısı ile akıllı mühürlerin konteynerin statüsü hakkında bilgi sunabilmekte, içerebileceği farklı teknolojiler (GPS, Sensör vb.) ile yetkisiz girişlerin, nem, sicaklık, kimyasal madde, basınç vb. parametrelerin tespit edilebilmesini sağlamaktadır. RFID teknolojinin konteyner limanı kapı giriş ve çıkış süreçlerinde de önemli faydaları bulunmaktadır. Geleneksel kapı sistemlerinde, kamyon ve konteyner numarasından tanıma, konteyner hasarını tespit etme, konteyner mührünün kontrolü vb. işler kapı görevlileri tarafından manuel olarak yapilmaktadır (Choi, Park, Park, Yoo ve Kwon, 2006, s.251-257). RFID tabanlı kapı sistemleri, okuyucular vasıtasıyla etiketli araçları, şoförlerini ve konteynerleri otomatik olarak taniyabilmektedir (Choi, Park ve Dong, 2007, s.372-377). Scholliers, vd., (2016) çalışmasında limana bağlı tedarik zincirlerindeki konteynerlerin bütünlüğünü arttırmaya yönelik teknolojik olanaklar tartışılmıştır. Bu çalışmada, olası çözümler, emühürler ve izleme cihazları gibi izleme ekipmanlarını eklemek, 
kameraları kullanarak çevreyi izlemek ve teknoloji tabanlı kapı işlemleridir. Limanlarda yaşanan araç kuyruklarının oluşması ve park etme, belgelendirme, veri güvenliği, sürücü tanımlama, mühür tanımlama, fiziksel hasar denetimi, konteyner ağırlığı, radyasyon muayenesi, gaz muayenesi, araç izleme vb. problemler konteynerlere monte edilmiş RFID tabanlı CSD ve sensörler, CCTV ve video analitiği, limanlardaki bilgi sistemleri ile bağlant1, ek gözetim için insansız hava araçları (drone) kullanımı ile çözümlenmeye çalışılmaktadır. RFID’ye ek olarak veya tek başına pek çok teknoloji kombin olarak konteyner taşımacılı̆̆ında kullanılabilmektedir. Bunlar GPS (Global Positioning System), sensörler, uydu mesajlaşma, cep telefonları, Bluetooth, UWB (Ultra-Wide Band: Ultra Geniş Band), Wi-Fi (Wireless Fidelity: Kablosuz Bağlantı Alanı), OCR (Optical Character Recognition: Optik Karakter Tanımlama) ve ZigBee (Kisa Mesafe Kablosuz Ağ Standartı)'dir (Yao, Chu ve Zang, 2012, s. 3507-3509). Konteyner terminallerinde RFID teknolojisinin sağladığ 1 faydalar Tablo 1'de özetlenmiştir.

\section{Tablo 1. RFID Teknolojisinin Konteyner Terminallerine Să̆ladı̆̆ı Faydalar}

- Tüm süreçlerde otomatik olarak anlık, eksiksiz ve doğru veri sağlanması,

- Terminalde kullanilan diğer sistemlere entegrasyonuna bağlı olarak departmanlar arasında etkin veri akışının sağlanması,

- Otomatizasyona bağlı olarak kâğıt israfında azalma,

- Terminal aktivitelerinin ve aktivite içindeki tüm insan, araç ve yüklerin takip edilebilmesi ve konum bilgilerinin alınabilmesine bağlı olarak tüm süreçlerin etkin yönetimi (aktivite planlama, kaynak tahsisi, saha yönetimi, rıhtım yönetimi, anlık oluşan problemleri ve değişikliklerin hemen tespit ederek çabuk reaksiyon verebilme vb.),

- Terminal aktivitelerinin ve aktivite içindeki tüm insan, araç ve yüklerin takip edilebilmesi ve konum bilgilerinin alınabilmesine bağlı olarak liman ve yük güvenliğinde artış,
- Diş araçların limanda kalış sürelerinde düşüş ve buna bağlı olarak araç trafiğinde azalma,

- Liman sahalarının optimum kullanımı,

- Kayıp, çalıntı, sahtecilik vb. illegal teşebbüslerde azalmaya bağlı olarak yük ve tedarik zinciri güvenliğinde artış,

- Terminale gelen konteyner bütünlüğünün güvence altına alınması,

- Konteyner denetim ve gümrük sürelerinde azalma,

- İşçi giderlerinde azalma,

- Konteynerlerin, hatalı elleçlenmesi, hatalı gönderimi ve kayıplarında azalma,

- İşlem sürelerinde (kapı, saha, yükleme vb.) ve hatalarındaki azalmaya bağlı olarak konteyner üretiminde artış,

- Etkin konteyner depo yönetimi,

- Terminal kaynaklarının (işgücü, ekipman vb.) optimum kullanımı,

- Operasyonel verimlilikte artış, 
- Sağlanan kaliteli ve doğru verilerin ışığında geleceğe yönelik etkin planlama avantaji,

- Kapı operasyonlarındaki etkin kullanımı ile beklemelerin azalması, insan hatalarının minimize edilmesi ve liman emniyetinde artış,

- Daha hizlı ve kaliteli hizmete bağlı olarak rekabet edebilirlikte artış

\section{Yöntem ve Model}

Önceki bölümlerde açıklandığı üzere konteyner limanlarında (terminallerinde) RFID teknolojisinin kullanım alanları ve sağladı̆̆ 1 faydalar çok sayıda olsa da bazı açılardan dezavantajları bulunmaktadır. Bunların en önemlilerinden birisi ilgili teknolojinin maliyetleridir. Bu bağlamda ilgili teknolojinin fayda-maliyet analizinin yapılması büyük önem taşımaktadır. Bir yatırımın, yatırım dönemi ve ekonomik ömrü boyunca sağlayacağı faydalar ile ortaya çıkacak maliyetlerin ölçülmesi, belli bir referans yılına indirgenerek karşılaştırılması, başa baş noktasının tespiti ve fayda-maliyet oranlarının bulunarak ekonomikliğinin ortaya konması gerekmektedir. Bu amaçla aşağıda maddeler halinde sunulan kabuller doğrultusunda, Tsai ve Huang (2012) çalışmasına farklı parametreler eklenerek oluşturulan yeni bir model ile ölçülebilir parametreler çerçevesinde konteyner terminallerinde RFID teknolojisinin kullanımına yönelik fayda-maliyet analizi yapılmıştır. Fayda-maliyet analizi, yatırımın ekonomik ömrü boyunca sağlaması beklenen gelirlerin, projenin gerektirdiği harcamalar ile karşılaştırılmasını içermektedir. Daha açı bir ifade ile, yatırımın ekonomik ömrü süresince beklenen gelirler, belirli bir iskonto oranı yardımıyla yatırımın başlangıç dönemindeki değerine (bugünkü net değer) indirgenmekte ve bu değer, yapılan yatırım harcamaları ile mukayese edilmektedir. Bir proje belirli bir maliyetle başlamakta, işletim giderleriyle ve periyodik bakım ve onarım maliyetleri ile devam etmektedir. Fayda ise süreç içerisinde gerçekleşmektedir. Karşılaştırma yapabilmek için ikisinin de aynı zamana indirgenmesi gerekmektedir. Analiz sonucu elde edilecek oranlar aşağıdaki gibi yorumlanmaktadır; 
F/M Oranı1.0: Ekonomik açıdan maliyetler faydaları aşmaktadır. Proje/yatırım ilerlememelidir.

F/M Oranı = 1.0: Maliyetler faydalara eşittir, bu da projenin/yatırımın devam etmesine izin verilmesi gerektiği anlamına gelmekle birlikte yapılabilirlik ile ilgili problemler bulunmaktadır.

F/M Oranı > 1.0: Faydalar maliyetleri aşmaktadır ve projenin devam etmesine izin verilmelidir. (Pan American Health Organization [PAHO],2016, s.77).

Oluşturulan fayda-maliyet modeli ve sonuçlarn aşağıdaki gibidir.

$(F \mid M)=\frac{\sum_{j=0}^{n} T F_{j}}{\sum_{j=0}^{n} T M_{j}} \quad(F:$ Fayda, M: Maliyet, $j:$ Yatırım yıl $)$

$T F_{j}=T K P M T_{j}+E M T_{j}+D M T_{j}$

$T K P M T_{j}=\sum_{j=1}^{n}\left(\left(T K P M_{R F I D \prime s i z}\right)_{j}-\left(T K P M_{R F I D \prime l i}\right)_{j}\right)$

$E M T_{j}=\sum_{j=1}^{n}\left(\left(E M_{R F I D \prime s i z}\right)_{j}-\left(E M_{R F I D \prime l i}\right)_{j}\right)$

$D M T_{j}=\sum_{j=1}^{n}\left(\left(D M_{R F I D \prime s i z}\right)_{j}-\left(D M_{R F I D \prime l i}\right)_{j}\right)$

$T F_{j}=j$. yıldaki Toplam Fayda

$T K P M T_{j}=j$. yıldaki Terminal Kapısı Personel Maliyetlerinden Tasarruf

$E M T_{j}=j$. yildaki Elleçleme Maliyetlerinden Tasarruf

$D M T_{j}=j$. yıldaki Dokümantasyon Maliyetlerinden Tasarruf

TKPM $M_{j}=j$. yıldaki Terminal Kapısı Personel Maliyetleri

$E M_{j}=j$. yıldaki Elleçleme Maliyetleri

$D M_{j}=j$. yıldaki Dokümantasyon Maliyetleri

$T M_{j}=K M+\sum_{j=1}^{n} \dot{\mathrm{I}} M_{j}$

$T M_{j}=j$. yıldaki Toplam Maliyet

KM=Kurulum Maliyet $i$

$\dot{\mathrm{I}} M_{j}=J$. Yıldaki Işletim (Bakım, Eğitim, Entegrasyon Vb) Maliyeti 


\section{Bulgular}

Konteyner terminalinde RFID teknolojisinin kullanımına yönelik F/M analizi için bir önceki bölümde açıklanan genel model kullanılarak, aşağıda belirtilen kabuller çerçevesinde bir senaryo oluşturulmuş ve ölçülebilir parametreler ile analiz edilmiştir.

- Çalışmanın konusunu konteyner terminalleri oluşturduğu için fayda ve maliyet parametreleri sadece terminal bazında belirlenmiştir.

- Taşıyıcı araçların, terminale girişi yapılan konteynerlerin ve çalışanların RFID etiketli kartlara sahip olduğu, sahip olmayanların etiketlendirildikten sonra limana giriş yaptığ kabul edilmiştir.

- Tüm dünya uygulamalarında geçerli olduğu üzere liman dışı taşıyıcı araçların ve konteynerlerin RFID etiketi maliyetlerinin taşıyıcı firmalar tarafından karşılandığı kabul edilmiştir.

- Fayda-maliyet analizinin yapıldığı limanın; yıllık 1.000 .000 TEU'luk (650.000 konteynerlik) elleçleme kapasitesi olduğu varsayılmıştır. Kapı sayısı 2 giriş ve 2 çıkış olmak üzere 4 adettir. Kapılardan yılda 450.000 araca işlem yapıldığ kabul edilmiştir. Toplam terminal sahası $200.000 \mathrm{~m} 2$ ve toplam rihtım sayısı 4 ve uzunluğu 900 metre olarak kabul edilmiştir. Ayrıca 3 adet raylı vinç, 7 adet mobil vinç ve 150 adet saha ekipmanı (tekerlekli vinç, istif makinesi, spreader, çekici, forklift vb) olduğu varsayılmıştır (Tüm senaryolar konteyner terminali yöneticilerinin ve tedarikçilerin görüşleri, kabulleri ve paylaşabildikleri veriler dikkate alınarak oluşturulmuştur).

Terminal Kapısı Personel Maliyetlerinden Tasarruf (TKPMT): RFID teknolojisini adapte eden terminaller özellikle kapı giriş süreçlerinde istihdam ettiği personel sayısından tasarruf edebilmektedir. Analizde konteyner terminalinde giriş-çıkış kapıları 2'şer adet olarak kabul edilmiştir. Her bir kapıda süreçleri hızlandırmak ve zaman kayıplarını engellemek için 2'şer kişi çalıştırılmaktadır. Bu çalışanlar günde 3 vardiya ve 8 'er saatten çalıştırılmaktadır. Bu bağlamda bu görev için istihdam edilen ortalama 24 ila 32 kişi (Terminal yetkililerince özellikle 
yoğunluk yaşanan vb. dönemlerde sayının 32'ye çıkarıldığ 1 belirtilmiştir) olduğu, aylık 6.000 TL brüt maaş ödendiği ve her yıl \%6 oranında zam aldıkları kabul edilmiştir (genel sektörel veriler doğrultusunda). Maaş ve zam oranları sektör ortalamaları dikkate alınarak belirlenmiştir. Bu kişiler, araç ve yük kontrollerinin (plaka, konteyner no, yük tipi vb) yanı sıra belge ve bilgi kontrollerini yapmaktadırlar. Kontrollerin manuel yapıldığ çalışanın ise fiziksel kontrolleri yaptığı kabul edilmiştir. RFID'li bir sistemde bu kontroller otomatik olarak yapıldığından her bir kapı ve vardiya için 2'şer eleman yerine 1'er eleman çalıştırılması yeterli olmaktadır. Başka bir deyiş̧le RFID’li sistem kullanıldığında, işçilik maliyetleri yarı yarıya azalmaktadır. Yıllar içerisinde ortalama çalışan sayısının sabit kalacağı kabul edilerek Tablo 2 oluşturulmuştur.

Tablo 2. RFID'siz ve RFID'li Sistemlere Göre Terminal Kapısı Personel Maliyetlerinden Tasarruf Miktarları

\begin{tabular}{|c|c|c|c|c|c|c|c|c|c|}
\hline \multirow[b]{2}{*}{$\begin{array}{l}\mathrm{Y} \\
11\end{array}$} & \multirow[b]{2}{*}{$\begin{array}{l}\text { Y1ll } \\
\text { 1k } \\
\text { Ma } \\
\text { aş } \\
\text { Artı }\end{array}$} & \multicolumn{3}{|c|}{ RFID'siz Sistem } & \multicolumn{5}{|c|}{ RFID'li Sistem } \\
\hline & & $\begin{array}{l}\text { Topla } \\
\mathrm{m} \\
\text { Çalış } \\
\text { an } \\
\text { Sayıs }\end{array}$ & $\begin{array}{l}\text { Aylik } \\
\text { Brüt } \\
\text { Maaş } \\
\text { (TL/ki } \\
\text { şi) }\end{array}$ & $\begin{array}{l}\text { Y1llık } \\
\text { Maaş } \\
\text { Topla } \\
\text { m1 } \\
(\mathrm{TL})\end{array}$ & $\begin{array}{l}\text { Topl } \\
\text { am } \\
\text { Çalış } \\
\text { an } \\
\text { Sayıs }\end{array}$ & $\begin{array}{l}\text { Aylik } \\
\text { Maaş } \\
\text { (TL/ki } \\
\text { şi) }\end{array}$ & $\begin{array}{l}\text { Yillık } \\
\text { Maaş } \\
\text { Topla } \\
\text { mi } \\
\text { (TL) }\end{array}$ & $\begin{array}{l}\text { İşçilik } \\
\text { Maliyetleri } \\
\text { nden } \\
\text { Tasarruf } \\
\text { Toplamı } \\
\text { (TI) }\end{array}$ & $\begin{array}{l}\text { İşçilik } \\
\text { Maliyetleri } \\
\text { nden } \\
\text { Tasarruf } \\
\text { Toplamı } \\
\text { TII) }\end{array}$ \\
\hline 1 & & & 6.000 & 2.304 . & & 6.000 & 1.152. & 1.152 .000 & 1.152 .000 \\
\hline 2 & & & 6.360 & 2.442 . & & 6.360 & 1.221. & 1.221 .120 & 2.373 .120 \\
\hline 3 & & & 6.742 & 2.588 . & & 6.742 & 1.294 . & 1.294 .387 & 3.667 .507 \\
\hline 4 & & & 7.146 & 2.744 . & & 7.146 & 1.372 . & 1.372 .050 & 5.039 .558 \\
\hline 5 & 6 & 32 & 7.575 & 2.908 . & 16 & 7.575 & 1.454 . & 1.454 .373 & 6.493 .931 \\
\hline 6 & & & 8.029 & 3.083 . & & 8.029 & 1.541 . & 1.541 .636 & 8.035 .567 \\
\hline 7 & & & 8.511 & 3.268 . & & 8.511 & 1.634 . & 1.634 .134 & 9.669 .701 \\
\hline 8 & & & 9.022 & 3.464 . & & 9.022 & 1.732 . & 1.732 .182 & 11.401 .883 \\
\hline 9 & & & 9.563 & 3.672 . & & 9.563 & 1.836 . & 1.836 .113 & 13.237 .996 \\
\hline 1 & & & 10.137 & 3.892. & & 10.137 & 1.946 . & 1.946 .280 & 15.184 .276 \\
\hline
\end{tabular}

Elleçleme Maliyetlerinden Tasarruf (EMT): RFID tabanlı bir konteyner terminalinde giriş çıkış kapılarından elde edilen tasarrufa ek olarak terminal sahalarında (yükleme/boşaltma sahaları, istif alanı, depolar vb.) icra edilen elleçleme faaliyetlerine yönelik ciddi tasarruflar (işçilik, enerji, zaman $\mathrm{vb}$ ) elde edilebilmektedir. Bu alanlarda liman yöneticilerinden beklenen; alanların, çalışanların ve ekipmanların optimum verimlilikte kullanımının sağlanması ve buna bağlı olarak, konteyner başına 
elleçleme maliyetlerinden tasarruf edilmesidir. RFID teknolojisine sahip bir liman ve etiketlendirilmiş yük, araç, ekipman kombinasyonuna bağlı olarak okuyuculardan alınacak veriler, terminal ana işletim sistemindeki bilgilerle anında ve hatasız olarak karşılaştırılabilmektedir. Olası bir eşleşme problemine anında müdahale edilebilmekte, gereksiz iş kayıpları önlenebilmekte ve sağlanacak anlık verilerle daha etkin bir elleçleme planlaması yapılabilmektedir. Miragliotta, Perego ve Tumino (2007) çalışmasına göre RFID tabanlı yönetilen bir limanda elleçleme maliyetleri \%4.3 oranında düşmektedir. Bu teknolojinin uygulandığ 1 limanlarda elleçleme maliyetlerinden elde edilen kazançlara yönelik yayınlanmış gerçek ve detaylı veri olmaması nedeniyle belirtilen çalışmadaki değer dikkate alınarak hesaplama yapılmıştır. Limanlar tarafından elleçleme işçileri ve kullanılan yakıttan toplam elde edilen tasarruf konteyner başına $0,55 €(\cong 3,5 \mathrm{TL}$ ) olarak belirtilmiştir (Euro kur değeri, TCMB tarafından açılanan 2019 yılındaki ortalama kuru değeridir). Yıllık konteyner üretimi artışı UNCTAD raporu doğrultusunda \% 4,5 olarak alınmıştır (UNCTAD,2019, s.18). Bu bilgiler ışığında Tablo 3 hazırlanmıştır. Bu değer UNCTAD 'in tüm ülke limanları için geçmiş verileri kullanarak hesapladığı ortalama bir değerdir.

Tablo 3. RFID'li Sistem İle Elleçleme Maliyetlerinden Tasarruf Miktarları

\begin{tabular}{llllll}
\hline Yil & $\begin{array}{l}\text { Yıllık } \\
\text { Konteyner } \\
\text { Artış Oranı }\end{array}$ & $\begin{array}{l}\text { Konteyner } \\
\text { Başına } \\
\text { Tasarruf }\end{array}$ & $\begin{array}{l}\text { Y1llık } \\
\text { Konteyner } \\
\text { Üretimi }\end{array}$ & $\begin{array}{l}\text { Elde Edilen } \\
\text { Toplam } \\
\text { Tasarruf }\end{array}$ & $\begin{array}{l}\text { Elde Edilen } \\
\text { Toplam Tasarruf } \\
\text { Miktarı (TL)- }\end{array}$ \\
\hline 1 & & & 650.000 & 2.275 .000 & 2.275 .000 \\
2 & & & 679.250 & 2.377 .375 & 4.652 .375 \\
3 & & & 709.816 & 2.484 .357 & 7.136 .732 \\
4 & & 741.758 & 2.596 .153 & 9.732 .885 \\
5 & $\mathbf{4}, 5$ & 375.137 & 2.712 .980 & 12.445 .865 \\
6 & & 810.018 & 2.835 .064 & 15.280 .929 \\
7 & & & 2.962 .642 & 18.243 .570 \\
8 & & & 884.560 & 3.095 .961 & 21.339 .531 \\
9 & & & 924.365 & 3.235 .279 & 24.574 .810 \\
10 & & & 965.962 & 3.380 .866 & 27.955 .676 \\
\hline
\end{tabular}

Dokümantasyon Maliyetlerinden Tasarruf (DMT): Limanlar, her yük ve araç için çeşitli süreçlere (kontrol, yükleme, boşaltma, konsolidasyon vb) yönelik olarak farklı departmanların (gümrük, muhasebe, operasyon vb) bilgilendirilmesi amacı ile irsaliye onay formu, konsolidasyon formu, 
araç onay formu vb belgeler düzenlemektedir. RFID tabanlı bir liman sisteminde; etiketlendirilmiş objeler, el terminalleri ve saha okuyucuları vasıtasıyla tanınacağından, bu tarz belgelerin düzenlenmesi minimize edilebilecektir. Çünkü bu teknolojinin kullanılması, ilgili belge ve bilgilere ihtiyaç duyan departmanların bunları sistemden güncel hali ile görebilmesini sağlayacak ve bürokratik ihtiyaçlar azalacaktır. Limana giriş yapan her bir araç ve konteyner için en az 1'er belgenin hazırlanma ihtiyacının ortadan kalkacağı ve mevcut piyasa şartlarında belge başına maliyetin 0,035 TL olduğu (2019 yılı ortalama değeri) ve her yıl bu değerin \%5 arttığ UNCTAD (2019) raporu doğrultusunda yıllık konteyner üretimi artışı ve buna bağlı olarak yıllık araç sayısı artışı \% 4,5 olarak kabul edilmiştir (United Nations Conference on Trade Development [UNCTAD],2019, s.18).

Tablo 4. RFID'siz ve RFID'li Sistemlere Göre Dokümantasyon Maliyetlerinden Min. Tasarruf Miktarlarn

\begin{tabular}{|c|c|c|c|c|c|c|c|c|}
\hline $\begin{array}{l}\mathrm{Y}_{1} \\
1\end{array}$ & $\begin{array}{l}\text { Birim } \\
\text { Doküma } \\
\text { nt } \\
\text { Maliyeti } \\
\text { (TL/adet }\end{array}$ & $\begin{array}{l}\text { Yıllık } \\
\text { Konteyn } \\
\text { er Artış } \\
\text { Oranı } \\
\text { Tahmini }\end{array}$ & $\begin{array}{l}\text { Yıllık } \\
\text { Araç } \\
\text { Artış } \\
\text { Oranı } \\
\text { Tahmi }\end{array}$ & $\begin{array}{l}\text { Yillık } \\
\text { Araç } \\
\text { Say1sı } \\
\text { (Yıllı } \\
\text { k) } \\
\end{array}$ & $\begin{array}{l}\text { Yillik } \\
\text { Kontey } \\
\text { er } \\
\text { Sayisı } \\
\text { (Adet/Y } \\
\end{array}$ & $\begin{array}{l}\text { Tasarru } \\
\text { f Edilen } \\
\text { Min. } \\
\text { Doküm } \\
\text { an } \\
\end{array}$ & $\begin{array}{l}\text { Yillik } \\
\text { Min. } \\
\text { Doküm } \\
\text { at. } \\
\text { Tasarru }\end{array}$ & $\begin{array}{l}\text { Dokümantas } \\
\text { yon } \\
\text { Maliyetlerind } \\
\text { en Tasarruf } \\
\text { Toplamı }\end{array}$ \\
\hline 1 & 0.04 & & & 650.0 & 650.000 & 1.300 .00 & 45.500 & 45.500 \\
\hline 2 & 0,04 & & & 679.2 & 679.250 & 1.358 .50 & 49.925 & 95.425 \\
\hline 3 & 0,04 & & & 709.8 & 709.816 & 1.419 .63 & 54.780 & 150.205 \\
\hline 4 & 0,04 & & & 741.7 & 741.758 & 1.483 .51 & 60.107 & 210.312 \\
\hline 5 & 0,04 & 45 & 45 & 775.1 & 775.137 & 1.550 .27 & 65.953 & 276.265 \\
\hline 6 & 0,04 & & & 810.0 & 810.018 & 1.620 .03 & 72.367 & 348.632 \\
\hline 7 & 0,05 & & & 846.4 & 846.469 & 1.692 .93 & 79.404 & 428.037 \\
\hline 8 & 0,05 & & & 884.5 & 884.560 & 1.769 .12 & 87.127 & 515.163 \\
\hline 9 & 0,05 & & & 924.3 & 924.365 & 1.848 .73 & 95.600 & 610.763 \\
\hline 10 & 0,05 & & & 965.9 & 965.962 & 1.931 .92 & 104.897 & 715.659 \\
\hline
\end{tabular}

Kurulum Maliyeti: RFID teknolojisi tabanlı bir sistemi uygulayacak olan limanlar yüksek maliyetler ile karşılaşmaktadır. Bunların en önemlisi kurulum maliyetleridir. Bu maliyetler genel olarak etiketler, okuyucular, antenler, bilgisayarlar, ăg ekipmanları vb. maliyetler ile ara yazılım (middleware) ve diğer uygulama yazılımlarının oluşturulması ya da satın alınmasına ait maliyetler olarak tanımlanmaktadır. Modelin maliyet parametrelerini oluşturan tüm veriler; ilgili alanda faaliyet gösteren tedarikçi firmalar tarafından, çalışmanın konusunu oluşturan 
bir terminale göre 2019 yılı için hesapladığı yaklaşık ve tahmini fiyatların ortalamalarından oluşmaktadır. İlgili yıllara ait maliyetlerin liman tarafından o yıl içerisinde ödeneceği kabul edilmiştir.

İşletim (bakım, eğitim vb) maliyeti: Adapte edilen teknolojiyi iş görür durumda tutmaya yönelik maliyetlerdir. Bunların en önemlileri eğitim, bakım ve süreç yenileme maliyetleridir. Genellikle RFID tabanlı sistemler, 6. yılında çok kapsamlı olarak yenilenmektedir. Bu maliyetler Tablo 5'te gösterilmiştir.

Tablo 5. Fayda Maliyet Analizinde Kullanilan Maliyet Tutarlarnin Yillar Bazındaki Dă̆ılımı

\begin{tabular}{lllll}
\hline Y1l & $\begin{array}{l}\text { Kurulum Maliyeti } \\
\text { (TL) }\end{array}$ & $\begin{array}{l}\text { İşletim Maliyeti } \\
(\mathrm{TL})\end{array}$ & $\begin{array}{l}\text { Toplam Maliyet } \\
(\mathrm{TL})\end{array}$ & $\begin{array}{l}\text { Kümulatif Toplam } \\
\text { Maliyet (TL) }\end{array}$ \\
\hline 0 & -5.256 .405 & - & -5.256 .405 & -5.256 .405 \\
1 & - & -1.409 .250 & -1.409 .250 & -6.665 .655 \\
2 & - & -1.325 .337 & -1.325 .337 & -7.990 .992 \\
3 & - & -1.221 .090 & -1.221 .090 & -9.212 .082 \\
4 & - & -1.202 .277 & -1.202 .277 & -10.414 .359 \\
5 & - & -1.349 .877 & -1.349 .877 & -11.764 .237 \\
6 & - & -4.339 .064 & -2.493 .165 & -14.257 .402 \\
7 & - & -1.895 .526 & -1.895 .526 & -16.152 .927 \\
8 & - & -1.742 .070 & -1.742 .070 & -17.894 .997 \\
9 & - & -1.646 .821 & -1.646 .821 & -19.541 .817 \\
10 & - & -1.703 .279 & -1.703 .279 & -21.245 .097 \\
\hline
\end{tabular}

Tüm bu maliyet ve fayda verileri doğrultusunda oluşturduğumuz genel tablo Tablo 6' da verilmiştir.

Tablo 6. Yatırım Yıllarına Göre Kümülatif Fayda Maliyet Farkı Tablosu

\begin{tabular}{|c|c|c|c|c|c|c|c|c|c|c|}
\hline $\begin{array}{c}Y \\
11\end{array}$ & $\begin{array}{l}\text { Kuru } \\
\text { lum } \\
\text { Maliy }\end{array}$ & $\begin{array}{l}\text { İşleti } \\
\text { m } \\
\text { Mali }\end{array}$ & $\begin{array}{l}\text { Topl } \\
\text { am } \\
\text { Mali }\end{array}$ & $\begin{array}{l}\text { Kümü } \\
\text { latif } \\
\text { Topla }\end{array}$ & $\begin{array}{l}\text { Term } \\
\text { Kap1 }\end{array}$ & $\begin{array}{l}\text { Elleçl } \\
\text { eme } \\
\text { Maliy }\end{array}$ & $\begin{array}{l}\text { Min. } \\
\text { Dokü } \\
\text { mant. }\end{array}$ & $\begin{array}{l}\text { Topl } \\
\text { am } \\
\text { Fayd }\end{array}$ & $\begin{array}{l}\text { Kümü" } \\
\text { latif } \\
\text { Topla }\end{array}$ & $\begin{array}{l}\text { KÜMÜL } \\
\text { ATİF } \\
\text { FAYDA }\end{array}$ \\
\hline 0 & - & - & - & - & - & - & - & - & - & - \\
\hline 1 & - & - & - & - & 1.152. & 2.275 . & 45.500 & 3.472. & 3.472 . & - \\
\hline 2 & - & - & - & - & 1.221. & 2.377 . & 49.925 & 3.648 . & 7.120 . & -870.072 \\
\hline 3 & - & - & - & - & 1.294. & 2.484 . & 54.780 & 3.833 . & 10.954 & 1.742 .36 \\
\hline 4 & - & - & - & - & 1.372. & 2.596 . & 60.107 & 4.028. & 14.982 & 4.568 .39 \\
\hline 5 & - & - & - & - & 1.454. & 2.712 . & 65.953 & 4.233 . & 19.216 & 7.451 .82 \\
\hline 6 & - & - & - & - & 1.541. & 2.835 . & 72.367 & 4.449. & 23.665 & 9.407 .72 \\
\hline 7 & - & - & - & - & 1.634. & 2.962. & 79.404 & 4.676. & 28.341 & 12.188 .3 \\
\hline 8 & - & - & - & - & 1.732. & 3.095 . & 87.127 & 4.915 . & 33.256 & 15.361.5 \\
\hline 9 & - & - & - & - & 1.836. & 3.235 . & 95.600 & 5.166. & 38.423 & 18.881.7 \\
\hline 1 & - & - & - & - & 1.946. & 3.380. & 104.89 & 5.432. & 43.855 & 22.610 .5 \\
\hline
\end{tabular}


Bir projenin belli bir zaman aralığında sağlayacağı tasarruf miktarları ile yatırım giderlerinin, gelecekteki değeri ile bugünkü değerinin farklı olduğu ve paranın zaman içerisinde değer kaybettiği ekonominin bir gerçeğidir. $\mathrm{Bu}$ gerçekten yola çıkılarak Formül 4.6'da belirtilen "Net Bugünkü Değer (NBD)" kavramı ortaya atılmıştır. $M_{t}$ ve $F_{t}$ olarak belirtilen ifadeler t.yıldaki maliyet ve tasarrufları, i olarak ifade edilen kavram ise indirgenme oranıdır. İndirgenme oranı, kullanılacağı alana göre farklılıklar gösterse de genellikle sermaye piyasasındaki ortalama mevduat faiz oranı olarak alınmaktadır.

$$
(F / M)_{N B D}=\frac{\sum_{t=0}^{n} F_{t}(1+i)^{-t}}{\sum_{t=0}^{n} M_{t}(1+i)^{-t}}=\frac{\left.\left.\left.F_{0}+\left(F_{1} / 1+i_{1}\right)^{1}\right)+\left(F_{2} / 1+i_{2}\right)^{2}\right)+\cdots+\left(F_{n} / 1+i_{n}\right)^{n}\right)}{\left.\left.\left.M_{0}+\left(M_{1} / 1+i_{1}\right)^{1}\right)+\left(M_{2} / 1+i_{2}\right)^{2}\right)+\cdots+\left(M_{n} / 1+i_{n}\right)^{n}\right)}
$$

Formül (7) kullanılarak Tablo 5'te belirtilen değerler, Türkiye Cumhuriyeti Merkez Bankası [TCMB] (2019)'e göre \%10,37 (2019 yılı sonu itibariyle sermaye piyasasındaki ortalama mevduat faiz orani) indirgenme oranı ile bugünkü değerlerine taşınır. Bu işlem sonucu oluşan veriler Tablo 7'de görülmektedir.

Tablo 7. Yatırım Yıllarına Göre Kümülatif Fayda Maliyet Farkı Tablosu (NBD $\% 10,37$ için)

\begin{tabular}{|c|c|c|c|c|c|c|c|c|c|c|c|}
\hline $\begin{array}{c}\mathrm{Y} \\
11\end{array}$ & $\begin{array}{l}\text { Kuru } \\
\text { lum } \\
\text { Mali } \\
\text { yeti } \\
\text { (TL) }\end{array}$ & $\begin{array}{l}\text { İşleti } \\
\text { m } \\
\text { Mali } \\
\text { yeti } \\
\text { (TL) }\end{array}$ & $\begin{array}{l}\text { Topl } \\
\text { am } \\
\text { Mali } \\
\text { yet } \\
\text { (TL) }\end{array}$ & $\begin{array}{l}\text { Küm } \\
\text { ulatif } \\
\text { Topla } \\
\mathrm{m} \\
\text { Maliy } \\
\text { et } \\
\text { (TL) }\end{array}$ & $\begin{array}{l}\text { Ter } \\
\text { m. } \\
\text { Kap1 } \\
\text { sı } \\
\text { İşçili } \\
\text { k } \\
\text { Mali } \\
\text { yt. } \\
\text { Tasa }\end{array}$ & $\begin{array}{l}\text { Elleçl } \\
\text { eme } \\
\text { Mali } \\
\text { yt. } \\
\text { Tasa } \\
\text { rruf } \\
\text { (TL) }\end{array}$ & $\begin{array}{l}\text { Min. } \\
\text { Dokü } \\
\text { mant. } \\
\text { Tasarr } \\
\text { ufu } \\
\text { (TL/Y1 } \\
\text { l) }\end{array}$ & $\begin{array}{l}\text { Topl } \\
\text { am } \\
\text { Fayd } \\
\text { a } \\
\text { (TL) }\end{array}$ & $\begin{array}{l}\text { Küm } \\
\text { ulatif } \\
\text { Topla } \\
\mathrm{m} \\
\text { Fayd } \\
\text { a } \\
\text { (TL) }\end{array}$ & $\begin{array}{l}\text { KÜMÜ } \\
\text { LATİF } \\
\text { FAYD } \\
\text { A } \\
\text { MALIY } \\
\text { ET } \\
\text { FARKI } \\
\text { (TL) }\end{array}$ & $\begin{array}{l}\text { F/ } \\
\mathbf{M} \\
\text { Or } \\
\text { an1 }\end{array}$ \\
\hline 0 & - & - & - & - & - & - & - & - & - & - & - \\
\hline 1 & - & - & - & - & 1.043 & 2.061 & 41.225 & 3.146 & 3.146 . & - & 0.4 \\
\hline 2 & - & - & - & - & 1.002 & 1.951 & 40.984 & 2.995 & 6.141. & - & 0,8 \\
\hline 3 & - & - & - & - & 962.7 & 1.847 & 40.745 & 2.851 & 8.992 . & 463.128 & 1,0 \\
\hline 4 & - & - & - & - & 924.6 & 1.749 & 40.506 & 2.714 & 11.70 & 2.367.5 & 1,2 \\
\hline 5 & - & - & - & - & 888.0 & 1.656 & 40.270 & 2.584 & 14.29 & 4.128 .1 & 1,4 \\
\hline 6 & - & - & - & - & 852.8 & 1.568 & 40.034 & 2.461 & 16.75 & 4.189 .0 & 1,3 \\
\hline 7 & - & - & - & - & 819.0 & 1.484 & 39.800 & 2.343 & 19.09 & 5.582 .7 & 1,4 \\
\hline 8 & - & - & - & - & 786.6 & 1.406 & 39.568 & 2.232 & 21.32 & 7.023 .8 & 1,4 \\
\hline 9 & - & - & - & - & 755.5 & 1.331 & 39.337 & 2.126 & 23.45 & 8.472 .3 & 1,5 \\
\hline 1 & - & - & - & - & 725.5 & 1.260 & 39.107 & 2.025 & 25.48 & 9.862 .4 & 1,6 \\
\hline
\end{tabular}




\section{Tartışma ve Sonuç}

Rekabet avantajını korumayı ve müşterilerine kaliteli hizmet vermeyi amaçlayan konteyner limanları, operasyon verimliliklerini, yük ve liman güvenliklerini arttırmaya yönelik olarak bilgi teknolojilerinden yararlanmaktadır. Bu teknolojilerden birisi de RFID (Radyo Frekansı ile Tanımlama) teknolojisidir. Tüm avantajları dışında dezavantajları da olan bu teknolojinin en büyük handikaplarından birisi maliyetleridir. Bu bağlamda konteyner limanında uygulanan RFID tabanlı bir sistemin ölçülebilir parametreler ile fayda-maliyet analizinin yapılarak, ilgili yatırımın ekonomikliğinin belirlenmesi önem arz etmektedir. Ayrıca perakende, lojistik ve sağlık sektörlerinde RFID teknolojisine yönelik birçok çalışma yapılmış olmasına ragmen konteyner terminallerinde RFID uygulamalarına yönelik çalışma sayısı azdır. Bu çalışmada RFID teknolojinin ölçülebilir fayda parametreleri çerçevesinde fayda-maliyet analizi yapılmıştır. Bir yatırımın yatırım dönemi ve ekonomik ömrü boyunca sağlayacağı faydalar ile ortaya çıkacak maliyetler ölçülmüş ve belli bir referans yılına indirgenerek karşılaştırılmıştır. Bu bağlamda; RFID teknolojisinin kullanıldığı, orta ölçekli (yıllık 1.000.000 TEU ve 650.000 konteynerlik elleçleme kapasiteli) bir konteyner terminalinin var olduğu senaryosu ile (İlgili senaryo liman saha yöneticilerinin görüşleri dikkate alınarak oluşturulmuştur) yapılan ve 10 yıllık süreyi kapsayan, fayda-maliyet analizine göre; bu tip bir konteyner terminalinde yapılacak RFID teknolojisi yatırımı; öngörülebilir maliyet ve ölçülebilir tasarruf parametrelerine göre ilk yılki kurulum aşamasından sonraki 3. yılda başa baş noktasına ulaşabilmektedir. Bu yatırımın 10 yıldaki toplam maliyeti NBD \%10,37'e göre 15.618.201- TL'dir. Bu büyüklükte bir yatırımdan sağlanacak ölçülebilir tasarruf miktarı ise 25.480.651 TL'dir. On yılın sonunda oluşan fayda-maliyet oranı 1,63'tür. Bu veri, terminaldeki RFID teknolojisi yatırımının uzun vadede faydalı olabilecek bir yatırım olduğunu göstermektedir. $\mathrm{Bu}$ oranın nispeten düşük olmasında döviz kuru beklentilerinin yüksek olması etkili olmaktadır. Günümüzde bu teknolojiye dönük AR-GE çalışmaları hızla devam etmektedir. Bu bağlamda önümüzdeki yıllarda, özellikle kurulum maliyetlerinde ciddi düşüşler beklenmektedir. Bu tip bir durumda proje çok daha kısa sürede başa baş noktasına ulaşabileceği ve fayda-maliyet 
oranının yükseleceği beklenebilir. Örneğin ilk yatırımın ve diğer yıllardaki maliyetlerin $1 / 3$ oranında düşmesi başabaş noktasını 1 yıl öne çekmekte, 10. yılın sonundaki fayda-maliyet oranını 2,45'e çıkarmaktadır. Ölçülemeyen faydaların da etkisiyle bu sürenin daha da kısalacağ1 düşünülmelidir. Kullanımı hızla artan RFID teknolojisine yönelik yapılacak araştırmalar pek çok liman işletmesi için önemlidir çünkü RFID'nin pazar potansiyeli çok yüksektir. Bu çalışma, konteyner terminal yöneticilerine -RFID özelinde- teknolojik yatırımlarına yönelik karar verirken fayda sağlayacağı düşünülmektedir. Fakat unutulmamalıdır ki; ancak geniş ölçekli bir yaygınlığa ulaştığında bu teknolojiden maksimum fayda sağlanabilecektir. İlgili teknolojinin limanlarda kullanımının artması ve sonraki yıllar içinde oluşan verilerin paylaşımı ile bu çalışmada oluşturulan model geliştirilebilecek, şu an için ölçülemeyen ve Tablo 1'de belirtilen pek çok parametre de modele eklenebilecektir. 


\title{
EXTENDED ABSTRACT
}

\section{A Benefit-Cost Analysis Study of Usage of RFID Technology in Container Ports}

\author{
Serdar Alnıpak \\ Nişantaşı Üniversity
}

A major change and development in Information Technologies (IT) experienced in every moment. This change influence many sectors such as the case of container transportation and container terminals. Ports which aim to provide high quality service to their customers and to maintain their competitive advantage, utilize IT for increasing their operating eficiency and security of cargo and port. In recent years one of the most prominent of these technologies is RFID (Radio Frequency Identification) technology. RFID technology is a technology that enables individually and automatically identification of objects using radio frequencies. Although RFID innovation was found many years ago, it has been advanced and developed in the last decade as costs are the main limitation in all use (Yadav ve Jha, 2019:1242). This technology is a widely used automatic identification technology to identify, track and detect multiple objects and/or people simultaneously via electromagnetic waves. The use of RFID in container terminals is basically done through 3 objects. These are; containers, equipment and vehicles used in loadingunloading and transportation operations (in and out of the port) and people in charge of the process. The main objectives are identification, tracking and enabling the security of cargo and port by way of locating passive and/or active tags objects. Both active and passive tags can be used together in container transportation. In general, active tags are 433 $\mathrm{MHz}$ and passive tags are $900 \mathrm{MHz}$. The active tags placed on the container are produced according to ISO 17363 and data can be written on it repeatedly. Since these tags are battery powered, they stay in sleep mode for certain periods of time. Passive tags used for containers are produced in ISO 10374.2 standards and have a frequency of 860-960 $\mathrm{MHz}$. UHF and MF readers are often preferred for RFID readers that read tags at control points (port entrance-exit gates, stowage areas, 
docks, storage areas, etc.). Depending on the data capacity of the tags the container number, the location information of the container, the weight of the container, the load type, the dangerous goods information, the seal control information, the damage detection information, the empty container detection results, the carrier vehicle information, the carrier vehicle driver information., carrier vehicle location information, container handling equipment (crane, interior truck, wagon, forklift, etc.) can be stored (Abajo, 2009: 5-11). With the help of readers installed inside and outside the port, the data on the active/passive tags attached to containers, vehicles, etc. can be read error-free and automatically, and the reads can be automatically reported to the system via a wireless network. Kaliszewski (2018) stated in his study that one of the criteria that defines the 5th generation ports is the use of RFID systems. RFID technology can be used for many applications. Some of these applications are; collection of highway tolls without the vehicle having to stop; identification of trucks/trucks located near the gates of factories, ports or logistics centers and the use of various information signs indicating the location of the cargo; identification of containers and truck trailers at ports, train stations and truck terminals, thus avoiding "lost" containers and trailers and effectively matching handling equipment and loads; identification of vehicles at regular stopping points (border crossings, weighing stations, checkpoints); identification of drivers violating the work / rest schedule, etc. (Batarlienè and Jarašūniene, 2016: 484).

Port security is of great importance due to both direct threats to life and property and the economic damage that may occur in supply chains. The benefits of RFID technology in container terminals are summarized in Table 1.

\section{Table 1. Benefits of RFID Technology's Usage in Container Terminals}

- Providing instant, complete and accurate data automatically in all processes,

- Ensuring effective data flow between departments, depending on its integration with other systems used in the terminal,

- Reduction in paper waste due to automation,

- Effective management of all processes
- Decrease in waiting times of external vehicles at the port and consequently a decrease in vehicle congestion,

- Optimum use of port areas,

- Increase in cargo and supply chain security due to a decrease in illegal attempts, stolen continers, forgery etc

- Ensuring the integrity of the containers, 


\begin{tabular}{|c|c|}
\hline $\begin{array}{l}\text { ction } \\
\text { de to } \\
\text { d all } \\
\text { the } \\
\text { on } \\
\text { and } \\
\text { zing } \\
\text { fety }\end{array}$ & $\begin{array}{l}\text { customs times, } \\
\text { - Reduction in worker expenses, } \\
\text { - Reduction in incorrect handling, incorrect } \\
\text { shipment and loss of containers, } \\
\text { - Increase in container production due to } \\
\text { the decrease in processing times (gates, yars, } \\
\text { loading, unloading processes etc.) and } \\
\text { errors, } \\
\text { - Effective } \\
\text { management, container } \\
\text { - Optimum use of terminal resources (labor, } \\
\text { equipment, etc.), } \\
\text { - Increase in operational efficiency, } \\
\text { - Reduction in thewaiting times of ships at }\end{array}$ \\
\hline
\end{tabular}

In this context ports which consider technology as an important factor in creating competitive advantage and take into account the fact that RFID technology is going to start to be used globally, will have to make strategic decisions about this technology. Because the adaptation of RFID technology to a container terminal is both costly and complicated process. In this context, choosing the most appropriate RFID application is strategically important for terminals which are planning to invest in RFID technology. Although there are many scholarly works in the different sectors, academic research on the use of RFID technology in container transportation and ports is poor.

Author aimed to apply benefit-cost analysis with measurable parameters for a container terminal where has been applied RFID technology to its all areas and determine the economy of related investment. For the benefit-cost analysis; we asume a medium-sized container terminal where has been applied RFID technology to its all areas and calculate the economy, benefit-cost ratio and break even point of related investment within the framework of measurable parameters.

In this context; The RFID technology investment to be made according to the cost-benefit analysis made with the scenario of a medium-sized (annual 1,000,000 TEU and 650,000 container handling capacity) container terminal and covering a period of 10 years, it can reach the breakeven point in the 3rd year in the basis of measurable 
savings parameters. The total cost of this investment in 10 years is TL $15,618.201$, according to NPV $10.37 \%$. The amount of measurable savings to be obtained from an investment of this size is 25,480,651 -TL. The benefit-cost ratio at the end of the decade is 1.63 . This data shows that the RFID technology investment in the terminal is an investment that can be beneficial in the long run. All scenarios have been created taking into account the opinions and acceptances of container terminal managers and suppliers and the data they share. The fact that this rate is relatively low due to the high exchange rate expectations. Today, R\&D studies for this technology is continuing rapidly. In this context, serious decreases are expected especially in installation costs in the following years. In such a case, it can be expected that the project will reach the breakeven point in a much shorter time and the benefit-cost ratio will increase. With the increase in the use of the relevant technology in the ports and the sharing of the data obtained in the following years, the model created in this study can be developed, and many parameters that cannot be measured at the moment can be added to the model.

\section{Kaynakça / References}

Abajo, V.O. (2009). Analysis of ICT solutions integration for tracking purposes in container terminal management and operatio. Thesis (Master). l'Escola d'Enginyeria de Telecomunicació, Universitat Politècnica de Catalunya.

Ali, A. ve Haseeb, M. (2019). Radio frequency identification (RFID) technology as a strategic tool towards higher performance of supply chain operations in textile and apparel industry of Malaysia. Uncertain Supply Chain Management, 7, 215-226, doi: 10.5267/j.uscm.2018.10.004.

Bandara, Y.M., Garaniya, V., Chin, C. and Leong, Z.H. (2015). Improving logistics management using foldable/collapsible containers: A case study. The Asian Journal of Shipping and Logistics, 31(1), $161-185$.

Banks, J., Hanny, D., Pachano, A.M. and Thompson, L.G. (2007) RFID Applied. 1st ed., John Wiley \& Sons, USA, 978-0471793656. 
Batarlienè, N. and Jarašūniene, A. (2016). Development of Advanced Technologies (AT) in green transport corridors. Procedia Engineering, $134,481-489$.

Choi, H.R., Park, J.P. and Dong, H.Y. (2007). A study on system dynamics modeling to strengthen the competitiveness of a container terminal. WSEAS International Conference on Computer Engineering and Applications, Gold Coast, Australia, January 17-19, 978-960-8457-584, 372-377.

Choi, H.R., Park, N.K., Park, B.J., Yoo, D.H. and Kwon, H.K. (2006). A Study on The Technology Development For Nonstop Automated Gate System. 2nd International Intelligent Logistics Systems Conference, 22-23 February, Port of Brisbane, Australia, 121-129.

Costa, F., Carvalho, M.D.S., Fernandes, J.M., Alves, A.C. and Silva, P. (2017). Improving visibility using RFID- the case of a company in the automative sector. Procedia Manufacturing, 13, 1261-1268.

Haddara, M. and Staaby, A. (2018). RFID Applications and adoptions in healthcare: A review on patient safety. Procedia Computer Science, 138, 80-88.

IDB (Inter-Amerıcan Development Bank) (2018). Digital Innovation in Maritime Supply Chains, Institutions for Development Sector, Discussion Paper № IDB-DP-577, 12.01.2020 tarihinde https://www.researchgate.net/publication/324862438 Digital Innova tion in Maritime Supply Chains Experiences from Northwestern Europe adresinden erişildi.

Kaliszewski, A. (2018). Fifth and sixth generatıon ports (5GP, 6GP)-evolution of economic and social roles of ports. 12.01 .2020 tarihinde https://www.researchgate.net/publication/324497972 fifth and sixt h generation ports $5 \mathrm{gp} 6 \mathrm{gp}-$

_evolution of economic and social_roles_of_ports adresinden erişildi.

Kirch, M., Poenicke, O. and Richter, K. (2017). RFID in logistics and production - applications, research and visions for smart logistics zones. Procedia Engineering, 178, 526 - 533.

M'hand, M.A., Boulmakoul, A., Badir, H. and Lbath, A. (2019). A scalable real-time tracking and monitoring architecture for logistics and transport in RoRo terminals. Procedia Computer Science, 151, 218-225. 
Miragliotta, G., Perego, A. and Tumino, A. (2007). RFID Technology in a container port: An activity-based model to assess costs and benefits. 02 Ocak 2012 tarihinde http://www.niinivirta.it/upl/modules/article/attachs/20090910172125 033.pdf adresinden erişildi.

Mladineo, M., Veza, I, Gjeldum, N., Crnjac, M., Aljinovic, A. and Basic, A. (2019). Integration and testing of the RFID-enabled smart factory concept within the learning factory. Procedia Manufacturing, 31, 384389.

Mondragon, A.E.C., Mondragon, C.E.C. and Coronado, E.S. (2017). ICT adoption in multimodal transport sites: Investigating institutionalrelated influences in international seaports terminals. Transportation Research Part A, 97,69-88.

Moreau, C-E. (2003). Radio frequency identification: The Technology and supply cham application. Thesis (Master). Lund University.

Özmen, A.G. ve Birgün, S. (2011). Radyo frekansı ile tanımlama sistemi seçiminde analitik hiyerarşi prosesi uygulaması. Havacılık Ve Uzay Teknolojileri Dergisi, 5(1), 81-88.

PAHO-Pan American Health Organization (2016). Cost-Benefit Analysis Methodology, Smart Hospitals Toolkit.

Panayides, P.M. (2007). Global supply chain integration and competitiveness of port terminals, ports, cities, and global supply chains. Ashgate Publishing, Hampshire, England, 18-19.

Scholliers, J, Permala, A., Toivonen, S. and Salmela, H. (2016). Improving the security of containers in port related supply chains. Transportation Research Procedia, 14, $1374-1383$.

Shin, S., Roh, H-S and Hur, S-H. (2018). Technical trends related to intermodal automated freight transport systems (AFTS). The Asian Journal of Shipping and Logistics 32(2), 161-169.

Tao, F., Kinkeung, L, Wang, Y-L and Fan, T. (2018). Determinant on RFID technology investment for dominant retailer subject to inventory misplacement. International Transactions Inoperational Research, 00(2018), 1-22, DOI: 10.1111/itor.12523.

TCMB (2019). 2019 Yil Mevduat Faizleri ,12.03.2020 tarihinde https://evds2.tcmb.gov.tr/index.php?/evds/portlet/lrcsQFWXtqo\%3 $\underline{\mathrm{D} / \mathrm{tr}}$ adresinden erişildi. 
Tengler, J., Kolarovzski, P. and Kolarovszká, Z. (2017). Identification and localization of transport units for selected company. Procedia Engineering , 178, $491-500$.

Tsai, F-M ve Huang, C-M. (2012). Cost-benefit analysis of implementing RFID system in port of Kaohsiung. Procedia-Social and Behavioral Sciences, 57, 40-46.

Tsilingiris P. S., Psaraftis H. N. and Lyridis D. V. (2007). Radio frequency identification technology in ocean container transport. Annual Conference of the International Association of Maritime Economists, IAME, Greece, Athens.

UNCTAD (2019). Review Of Maritime Transport, United Nations Publications, New York, USA.

$\mathrm{Xu}, \mathrm{K}$. , Zhen, H, Li, Y. and Yue, L. (2017). Comprehensive monitoring system for multiple vehicles and its modelling study. Transportation Research Procedia, 25, 1824-1833.

Yadav, S. and Jha, P. (2019). RFID technology: An overview. International Journal of Trend in Scientific Research and Development, 3(3), 1242-1245.

Yan, B., Liu, L., Liu, S. and Yang, J. (2018). Influencing factors in the application of RFID technology in the supply chain. The Engineering Economist, 63(1), 1-19.

Yao, W., Chu, C-H. and Zang, L. (2012). The adoption and implementation of RFID technologies in healthcare: A literature review. Journal of Medical Systems, 36(6), 3507-3525.

Zhong, R.Y. (2019). RFID Data driven performance evaluation in production systems. Procedia CIRP, 81, 24-27.

\section{Kaynakça Bilgisi / Citation Information}

Alnıpak, S. (2021). Konteyner limanlarında RFID teknolojisinin kullanımına yönelik bir fayda maliyet analizi çalışması. OPUSUluslararası Toplum Araştırmaları Dergisi, 18(Yönetim ve Organizasyon Özel Sayıs1), 1614-1642. DOI: 10.26466/opus.833607. 